\begin{tabular}{|c|c|c|c|c|c|}
\hline \multicolumn{3}{|c|}{ Energy-levels } & \multirow[b]{2}{*}{ Band systems } & \multirow[b]{2}{*}{$\underset{\text { (volts) }}{\text { Appearance potentials }}$} & \multirow[b]{2}{*}{ Remarks } \\
\hline Singlets & $\begin{array}{c}\text { Energy } \\
\text { (volts) }\end{array}$ & Triplets & & & \\
\hline \multirow[t]{3}{*}{$\begin{array}{c}X^{1} \Sigma_{g}^{+} \\
\text {(ground-state) } \\
\end{array}$} & 0 & & \multirow{2}{*}{$\begin{array}{c}A^{3} \Sigma_{u}^{+} \rightarrow X^{1} \Sigma_{g}^{+} \\
\text {Vegard - Kaplan }\end{array}$} & & \multirow[t]{2}{*}{ Forbidden transition } \\
\hline & $6 \cdot 2$ & $A^{3} \Sigma_{u}^{+}$ & & & \\
\hline & $7 \cdot 3$ & $B^{3} \Pi_{a}$ & $\begin{array}{l}B^{3} \Pi_{g} \rightarrow A^{s} \Sigma_{u}^{+} \\
\text {First positive }\end{array}$ & $9 \cdot 3(\mathrm{~S}), 9 \cdot 4(\mathrm{~V}), 9 \cdot 5(\mathrm{D})$ & $\begin{array}{l}\text { Fully developed on excitation of } \\
\text { second positive, maximum } \\
\text { intensity at } \sim 15 \text { volts }\end{array}$ \\
\hline \multirow[t]{3}{*}{$a^{1} \Pi_{q}$} & $8 \cdot 5$ & & & & \\
\hline & 11 & $C \cdot \Pi_{u}$ & $\begin{array}{c}C^{3} \Pi_{u \rightarrow B^{3} \Pi_{g}} \\
\text { Second positive }\end{array}$ & $\begin{array}{c}12(\mathrm{D}), 13(\mathrm{~S}), 13 \cdot 16(\mathrm{~T}, \\
\mathrm{W}), 13 \cdot 4(\mathrm{~V})\end{array}$ & $\begin{array}{c}\text { Maximum intensity } \\
\text { volts }\end{array}$ \\
\hline & $12 \cdot 8$ & $D^{9} \Sigma_{u}^{+}$ & $\begin{array}{r}D^{3} \Sigma_{u}^{+} \rightarrow B^{3} \Pi_{g} \\
\text { Fourth positive }\end{array}$ & 15 (D) & Maximum $\underset{\text { intensity }}{\text { volts }}$ at $\sim 20$ \\
\hline $\begin{array}{c}b \\
\text { (8 levels) }\end{array}$ & $\left\{\begin{array}{c}12 \cdot 5 \\
14\end{array}\right.$ & & & & \\
\hline Doublets & & & \multirow{3}{*}{$\begin{array}{l}B^{\prime 2} \Sigma_{u}^{+} \rightarrow X^{\prime 2} \Sigma_{g}^{+} \\
\text {First negative }\end{array}$} & \multirow{3}{*}{$18(\mathrm{D}), 19(\mathrm{~S})$} & \multirow{3}{*}{ Maximum $\underset{\text { intensity }}{\text { volts }}$ at $\sim 80$} \\
\hline$X^{\prime 2} \Sigma_{g}^{+}$ & $15 \cdot 6$ & & & & \\
\hline$B^{\prime 2} \Sigma_{u}^{+}$ & $18 \cdot 7$ & & & & \\
\hline
\end{tabular}

(S), Sponer ; (D), Duncan; (T, W), Thompson and Williams ; (V), Vegard.

them, strongly suggests that the primary population of the $B^{3}$-vibrational-levels, below the $a^{1} 11$-level, is due to collisions of the second kind between slow electrons and molecules in the $\alpha^{1} i_{1}$-state, while the secondary population of the $B^{3}$ Il-levels, especially those which lie above the $a^{1} L_{1}$-level, results from the emission of the second positive bands $C^{3} \Pi \rightarrow B^{3} \Gamma_{\perp}$. A further factor contributing to the population of the $B^{3} \Pi$-levels, when $b$ is excited, would be collisions of the second kind between slow electrons and molecules in the $b$-state. The fourth positive system $D^{3} \Sigma \rightarrow B^{3} \Pi$ appears at 15 volts when certain of the $b$-levels which lie above the $D^{3} \Sigma$-level become popu. lated, and reaches a maximum intensity at approximately 20 volts. Owing to the metastability of the $A^{3} \sum$-level, numerous collisions of the second kind with slow electrons will be probable. A radiationless $A^{3} \Sigma \rightarrow X^{1} \Sigma$ transition will therefore be more likely than the emission of the Vegard - Kaplan bands in most usual forms of discharge in nitrogen. The first negative system $B^{\prime 2} \Sigma \rightarrow X^{\prime 2} \Sigma$ of $N_{2}^{+}$will be excited directly by first-kind collision between ground-state $X^{1} \Sigma \mathrm{N}_{2}$ molecules and fast electrons.

The mechanism thus adequately accounts for the observed excitation potentials in terms of known levels of nitrogen. Further facts in its favour are :

(1) It is in accordance with the Franck-Condon principle in initial excitation.

(2) There is no change in multiplicity in the initial excitation.

(3) The recently proposed $g$ symmetry of the $a^{1} \Pi$-level ${ }^{5}$ renders that level metastable, thus raising the excitation life-time and making collisions of the second kind even more probable. Although the metastability tends to make the initial excitation less probable, the fact that the singlet bands appear in absorption shows that it can, and does, occur with a greater probability than the singlet-triplet excitation. The long path-length required for this absorption to occur provides experimental evidence for the metastability, as was pointed out by Herzberg 5 .

The above ideas are a result of work attempting to correlate spectroscopic and electrical observations on a glow discharge in nitrogen. Should the suggested mechanism prove to be correct, it may have an important bearing on auroral excitation, since many current theories of the aurora include direct singlettriplet excitation of neutral nitrogen, $\mathrm{N}_{2}$, by electrons.

I should like to express my grateful thanks to Dr. R. W. B. Pearse for valuable discussions on this subject.

${ }^{1}$ Duncan, Astrophys. J., 62, 145 (1925). Sponer, Z. Phys., 34, 622

(1925). Thompson and Williams, Proc. Roy. Soc., A, 147, 584

(1934): Langstroth, Proc. Roy. Soc., A, 146, 166 (1934); 150 , (1934). Langstroth, Proc. Roy. Soc., A, 146, $166(1934)$
371 (1935). Vegard, Geofys. Pub., 12, No. 12, 1 (1940).

2 Herzberg, Phys. Rev., 69, 362 (1946). Gaydon, "Dissociation Energies", 155 (1947).

${ }^{3}$ Gaydon, loc. cit.

"Mott and Massey, "The Theory of Atomic Collisions", 192.

${ }^{5}$ Herzberg, Nature, 161, 283 (1948).

\section{INTERNATIONAL GEOLOGICAL CONGRESS}

DREPARATIONS are now well advanced for the Eighteenth Session of the International Geological Congress. So far about 1,500 geologists, representing some sixty countries, have registered as members. The programme of long excursions associated with the Congress begins on August 7.

The Session will be formally inaugurated at a meeting of the General Assembly in the Royal Albert Hall on August 25, when Mr. Herbert Morrison will welcome the delegates and members on behalf of the British Government, and Sir John Anderson, honorary president of the General Organising Committee, will speak on behalf of that Committee. Prof. H. H. Read, president of the Geological Society of London, is president-designate of the Session. 
During the following days there will be an extensive series of sectional meetings, at which about two hundred and fifty papers, of which only a few ean be mentioned in this notice, and covering a very wide range of topics, are due to be presented.

In the Section on Problems of Geochemistry, questions connected with the development and migration of magmas and the genesis of ore deposits, the geochemical history of single elements, and the origin of serpentines will be discussed by distinguished contributors, including Dr. N. L. Bowen of Washing. ton, Prof. H. von Eckermann of Stockholm, Prof. P. Niggli of Zurich and Prof. W. Wahl of Helsingfors. In another petrological section, devoted to "Metasomatic Processes in Metamorphism", the "magma. tists' and the 'transformists' will present contrasting views on the respective importance of magmatic and hydrothermal penetration and of solid diffusion in the process of granitization and of metamorphism in general. The contributors include Prof. P. Eskola of Finland, Prof. N. H. Magnusson of Stockholm, Prof. E. Wegmann of Neuchatel, Prof. H. G. Backlund of Uppsala, and Prof. Ian Campbell of California.

Stratigraphical and palæontological problems will be discussed by several sections. The Section on Rhythm in Sedimentation will include papers by Prof. R. C. Moore, Dr. H. R. Wanless, and other American authors on cyclic sedimentation in the Palæozoic Rocks of the United States, and by Prof. G. F. Troedsson of Stockholm and other authors on rhythm in the Mesozoic and Tertiary sediments of Europe. Prof. A. Renier of Brussels, Dr. S. J. Dijkstra of Heerlen, Prof. Y. C. Sun of Peiping, Dr. J. J. Gorsky of Leningrad, and Dr. F. K. G. Mullereid of Mexico City are among contributors who will deal with general and regional problems of facies correlation in the Section on Faunal and Floral Facies and Zonal Correlation. The correlation of continental vertebrate-bearing rocks will be discussed in a separate section, and the overseas contributors include Dr. C. Teixeira of Lisbon, Mlle. M. Richard of Algiers, Dr. R. A. Stirton of California and Prof. Erik Stensiö of Stockholm. This Section will also hold a joint meeting with the Section on the PliocenePleistocene Boundary. The latter will attempt to reach an agreed definition of the lower limit of the Pleistocene System by synthesis of the views of specialist contributors, including Dr. L. S. B. Leakey of Kenya, Dr. A. Halicka of Warsaw, Dr. D. N. Wadia of India, Prof. van der Vlerk of Leyden, Prof. C. Migliorini of Florence and Prof. C. Arambourg of Paris. Another section will discuss the relation between earth movements and organic evolution, and includes papers by Drs. K. Zapletal and L. V. Čpek of Czechoslovakia, Academician V. A. Obruchev of Moscow, and Dr. A. Chavan of Nanterre.

An interesting field of inquiry is covered by the Section on the Geology of Sea and Ocean Floors. In this a number of American geologists will describe recent work on submarine geology of the Northern Marshalls, including recent borings on Bikini Atoll; and Prof. C. Francis-Bœuf of Paris will speak of the use of the 'Bathyscaphe-Piccard-Cosyns' in submarine studies. Other contributors are Prof. R. M. Field of Princeton, Prof. P. H. Kuenen of Groningen, and Dr. J. S. Lee of Nanking.

Three sections are specifically devoted to applied geology. A symposium on the geology, paragenesis and reserves of the ores of lead and zinc has been prepared under the editorship of Dr. K. C. Dunham and will be discussed by a special section. Its assess- ment of world reserves suggests that little more than about nineteen years production of lead ores and twenty-four years production of zinc ores can be foreseen. The Section on the Geological Results of Applied Geophysics will deal with recent magnetic, electrical, gravitational and seismic work on diverse problems in many countries. The Section on the Geology of Petroleum will include a wide range of papers on general and regional subjects, among which recent work in the oilfields of the Middle East is prominent.

There is also a section in which a great variety of miscellaneous papers will be presented. Among these, tectonic studies predominate, and the authors include Prof. A. Noe-Nygaard of Copenhagen, Prof. O. Holtedahl of Oslo, Prof. A. Demay of Paris, and Dr. A. Heim of Zurich.

The Association des Services Géologiques Africains will hold a series of open meetings at which a synthesis of research on African geology during the last decade will be attempted, and problems of correlation within the African continent will be discussed. The International Palæontological Union will also hold open meetings, including one specially devoted to the stratigraphical use of Foraminifera and another to the nomenclature of fossils. A series of special meetings on the mineralogy and geology of clays has been organised in conjunction with the Clay Minerals Group of the Mineralogical Society.

Three major items in the technical programme are special addresses on the structural history of Britain, by Sir Edward Bailey and Prof. O. T. Jones, who will respectively deal with Scotland and with England and Wales; and a colour film and lecture on the new Mexican volcano Paricutin, presented by Dr. F. H. Pough of the American Museum of Natural History.

During the period of the Session receptions will be given by H.M. Government, by the Geological Society of London, the University of London and a number of other authorities and institutions.

A series of ninety-six day and half-day excursions demonstrating the geology of south-eastern England will take place during the period August 20-September 4. After the closing meeting of the General Assembly on September 1, there will also be another series of seventeen long excursions covering practically the whole of Great Britain and Eastern Ireland.

\section{CONDENSATION OF INTER- STELLAR MATERIAL INTO STARS}

H. HOYLE has suggested (Mon. Not. Roy. Astro. H. Soc., 107, 4; 1948) a criterion for determining the degree of condensation of interstellar material into stars. Observational data for disk-shaped nebulæ, such as $M 31$ and $M 33$, suggest that only a small fraction of the total mass is in the form of stars, whereas Oort has found that the elliptical nebula NGC 3115 must be almost entirely composed of stars. The paper is devoted to a consideration of the factors that determine the fraction by mass of $a$ nebula that is condensed into stars, and a new method for attacking this problem is developed which suggests that condensing stars with masses exceeding 0.2 that of the sun must become rotationally unstable before reaching the main sequence stage, and such stars must evolve by ejecting material 